\title{
Revisiting plant biological nitrification inhibition efficiency using multiple archaeal and bacterial ammonia-oxidising cultures
}

\author{
Jasmeet Kaur-Bhambra ${ }^{1}$ - Daniel L. R. Wardak ${ }^{1}$ - James I. Prosser ${ }^{1} \cdot$ Cécile Gubry-Rangin $^{1}$ (1) \\ Received: 31 July 2020 / Revised: 13 November 2020 / Accepted: 14 December 2020 / Published online: 25 January 2021 \\ (C) The Author(s) 2021
}

\begin{abstract}
Nitrification is a major process within the nitrogen $(\mathrm{N})$ cycle leading to global losses of $\mathrm{N}$, including fertiliser $\mathrm{N}$, from natural and agricultural systems and producing significant nitrous oxide emissions. One strategy for the mitigation of these losses involves nitrification inhibition by plant-derived biological nitrification inhibitors (BNIs). Cultivation-based studies of BNIs, including screening for new compounds, have predominantly investigated inhibition of a single ammonia-oxidising bacterium (AOB), Nitrosomonas europaea, even though ammonia oxidation in soil is usually dominated by ammonia-oxidising archaea (AOA), especially in acidic soils, and AOB Nitrosospira sp., rather than Nitrosomonas, in fertilised soils. This study aimed to assess the sensitivity of ammonia oxidation by a range of AOA and AOB pure cultures to BNIs produced by plant roots (methyl 3-(4hydroxyphenyl) propionate, sakuranetin and 1,9-decanediol) and shoots (linoleic acid, linolenic acid and methyl linoleate). AOA were generally more sensitive to BNIs than AOB, and sensitivity was greater to BNIs produced by shoots than those produced by roots. Sensitivity also varied within AOA and AOB cultures and between different BNIs. In general, N. europaea was not a good indicator of BNI inhibition, and findings therefore highlight the limitations of use of a single bioassay strain and suggest the use of a broader range of strains that are more representative of natural soil communities.
\end{abstract}

Keywords AOA $\cdot$ AOB $\cdot$ BNI $\cdot$ Thaumarchaeota $\cdot$ Plant $\cdot$ Culture $\cdot$ Nitrosomonas europaea

\section{Introduction}

The global $\mathrm{N}$ cycle is largely driven by soil microbial $\mathrm{N}$ transformations within which nitrification, the oxidation of ammonia $\left(\mathrm{NH}_{3}\right)$ to nitrate $\left(\mathrm{NO}_{3}{ }^{-}\right)$, is a key process. Nitrification involves initial oxidation of $\mathrm{NH}_{3}$ to nitrite $\left(\mathrm{NO}_{2}{ }^{-}\right)$by ammonia-oxidising archaea and bacteria (AOA and $\mathrm{AOB}$ ), which is then oxidised to $\mathrm{NO}_{3}{ }^{-}$by nitrite-oxidising bacteria (NOB), while comammox can perform both steps. A key factor driving the soil $\mathrm{N}$ cycle, and global agricultural production, is the application of $\mathrm{N}$ fertilisers, which comprise more than $50 \%$ of $\mathrm{N}$ input. $\mathrm{N}$ fertiliser applications are projected to increase from $105 \mathrm{Mt}$ (million tonnes) per year in 2010 to $\sim 180$ Mt per year by 2050 (Subbarao et al. 2015), and nitrification is

Cécile Gubry-Rangin

c.rangin@abdn.ac.uk

1 School of Biological Sciences, University of Aberdeen, St Machar Drive, Aberdeen AB24 3UU, UK responsible for $\mathrm{N}$ losses of up to $70 \%$ in natural and agricultural systems (Subbarao et al. 2015; Coskun et al. 2017). The mobility of anionic $\mathrm{NO}_{3}^{-}$leads to significant leaching and pollution of water bodies or, under anaerobic conditions, to reduction of $\mathrm{NO}_{3}{ }^{-}$to dinitrogen $\left(\mathrm{N}_{2}\right)$ and nitrous oxide $\left(\mathrm{N}_{2} \mathrm{O}\right)$, a highly potent greenhouse gas with an estimated global warming potential 265 times greater than $\mathrm{CO}_{2}$ (IPCC 2014). Significant $\mathrm{N}_{2} \mathrm{O}$ emissions are also associated directly with the activity of $\mathrm{AOB}$ and/or AOA, through nitrifier denitrification, incomplete oxidation of hydroxylamine and nonenzymatic conversion of nitrification products and intermediates (Prosser et al. 2019). Strategies for the control of nitrification in agroecosystems are therefore required to reduce the $\mathrm{N}$ footprint, reduce $\mathrm{N}_{2} \mathrm{O}$ emissions and increase fertiliser nitrogen use efficiency (NUE).

One strategy employed to increase NUE is the application of synthetic nitrification inhibitors (SNIs), such as nitrapyrin, dicyandiamide (DCD) and 3,4-dimethylpyrazole phosphate (DMPP) (Ruser and Schulz 2015). However, efficient inhibition requires high amounts of SNIs, and their relatively high costs, low solubility in water, susceptibility to leaching and potential degradation by soil microbial communities restrict 
their widespread use in farming systems (Ruser and Schulz 2015). Nonetheless, competition for $\mathrm{N}$ in soils has led to the evolutionary adaptation in a wide range of grasses, including important crops (sorghum rice, wheat and maize), to improve $\mathrm{N}$ uptake and assimilation by production of biological nitrification inhibitors (BNIs) from roots or following decomposition of shoots (Subbarao et al. 2009; Coskun et al. 2017; Subbarao et al. 2015).

All currently characterised BNIs inhibit ammonia monooxygenase (AMO), which catalyses the first and ratelimiting step of ammonia oxidation, oxidation of $\mathrm{NH}_{3}$ to hydroxylamine $\left(\mathrm{NH}_{2} \mathrm{OH}\right)$. However, subsequent energygenerating pathways for the conversion of $\mathrm{NH}_{2} \mathrm{OH}$ to $\mathrm{NO}_{2}{ }^{-}$ differ in AOA and AOB (Stein 2019). In addition, the two most active AO groups in soil, AOA and Nitrosospira, the dominant AOB in most soils (Aigle et al. 2019), occupy different ecological niches (Prosser and Nicol 2012), with Nitrosospira dominating $\mathrm{NH}_{3}$-oxidising activity in Nfertilised soils, while AOA dominate soils with low ammonium $\left(\mathrm{NH}_{4}{ }^{+}\right)$supply (Hink et al. 2018) or low pH (GubryRangin et al. 2010, 2011). Despite the importance of these two groups of AO, and the very low abundance of Nitrosomonas in soil, BNI inhibition bioassays (e.g. AO inhibition assay through incubation of cultivated strains with root or shoot extracts or exudates) have been performed using a single AOB strain, Nitrosomonas europaea (Subbarao et al. 2015). These bioassays often utilise a genetically modified $N$. europaea that carries genes for bioluminescence activity from the marine bacteria Vibrio harveyi coupled to ammonia oxidation (Iizumi et al. 1998). This approach presents certain constrains, including the outsourcing of the genetically modified $N$. europaea strain and the laboratory requirement to use genetically modified organisms. In contrast, the Griess reagent test is used, which measures the nitrification activity of nongenetically modified ammonia oxidisers by determining the accumulated nitrite, an alternative high-throughput approach that is easily applicable to one or multiple ammonia-oxidiser strains.

Cultivation-based studies have shown variability in sensitivity to SNIs within $\mathrm{AOB}$ and AOA, with the AOB Nitrosospira multiformis being more sensitive to some SNIs than the AOA Nitrososphaera viennensis (Shen et al. 2013). In contrast, soil studies indicate greater sensitivity of AOA to BNI produced by some Brachiaria humidicola (Bh) hybrids, but not others (Subbarao et al. 2009). There is also evidence that the inhibition efficiency of BNIs depends on several factors, including BNI concentration (Nardi et al. 2012), soil pH (Lu et al. 2019), plant genotype (Subbarao et al. 2006, 2009; O'Sullivan et al. 2016; Sun et al. 2016) and AOA or AOB community composition ( $\mathrm{Lu}$ et al. 2019). BNIs can be released as secondary metabolites from plant roots and stem tissues and as tannins, phenolic acids or flavonoids released from decaying leaves and stems (Coskun et al. 2017). The former BNIs are likely to be concentrated near the rhizosphere, while the latter will either be evenly distributed throughout the soil or be more abundant in upper soil horizons. There is evidence for the stimulation of AOA growth in the rhizosphere, possibly through increased nutrient supply or protection against abiotic stress (Taffner et al. 2019), and for production, by AOA, of secondary metabolites promoting plant growth and protection against pathogenic bacteria and fungi (Song et al. 2019). In addition, a greater abundance of AOA than AOB has been reported in the rhizosphere of several plants, including rice (Chen et al. 2008; Ke et al. 2013), wheat (Ai et al. 2013), maize (Wattenburger et al. 2020) and grasses (Thion et al. 2016).

These findings suggest that meaningful assessment of the efficiency of BNIs should focus on a larger and more representative set of soil ammonia oxidisers than $N$. europaea, and lead to the following hypotheses: (H1) AOA are more sensitive than AOB to BNIs; $(\mathrm{H} 2)$ relative inhibition of AOA and $\mathrm{AOB}$ will depend on the source of BNIs, with greater sensitivity of $\mathrm{AOB}$ to root-derived BNIs and similar responses of $\mathrm{AOA}$ and $\mathrm{AOB}$ to those derived from shoots. (H3) $N$. europaea is not an appropriate model AO for bioassay of BNI inhibition of soil AO. This study aimed to test these hypotheses using ammonia-oxidiser cultures (rather than soil incubations) by comparing the effect of three root-derived [methyl 3-(4-hydroxyphenyl) propionate (MHPP), 1,9decanediol (DD) and sakuranetin (SKNT)] and three shootderived [methyl linoleate (ML), linoleic acid (LA) and linolenic acid (LNA)] BNIs on N. europaea and on several $\mathrm{AOA}$ and $\mathrm{AOB}$ cultures that are representative of soil $\mathrm{AO}$ communities.

\section{Materials and methods}

\section{Cultivation of ammonia oxidisers}

Three AOA strains were investigated (see Table 1): Nitrososphaera viennensis, isolated from an Austrian $\mathrm{pH} 8$ garden soil (Tourna et al. 2011), Candidatus Nitrosotalea sinensis, isolated from an acidic agricultural soil (LehtovirtaMorley et al. 2011), and Ca. Nitrosocosmicus franklandus, isolated from a Scottish pH 7.5 agricultural soil (LehtovirtaMorley et al. 2016). AOA were grown in a modified freshwater medium described by Tourna et al. (2011) (N. viennensis) and Lehtovirta-Morley et al. $(2011,2016)(C a$. N. sinensis and $C a$. N. franklandus). Four AOB strains were also investigated: N. europaea ATCC 19718 and N. multiformis ATCC 25196, obtained from NCIMB (http://www.ncimb.com/); Nitrosospira tenuis NV12, isolated from a Hawaiian soil (Harms et al. 1976); and Nitrosospira briensis 128, isolated from an acid agricultural soil (Rice et al. 2016). AOB were grown using the modified Skinner and Walker medium 
Table 1 Growth media, incubation temperatures and maximum specific growth rates $\left(\mu_{\max }\right)$ of AOA and AOB in the presence and absence of $0.1 \%$ DMSO. $\mu_{\max }$ values are presented as the mean and standard error (s.e.) of triplicate cultures and are compared with values reported in the cited references

\begin{tabular}{lllllll}
\hline Organism & Group & $\mu_{\max }\left(\mathrm{h}^{-1}\right)$ & $\mu_{\max }$ with DMSO $\left(\mathrm{h}^{-1}\right)$ & $\begin{array}{l}\text { Reported } \\
\mu_{\max }\left(\mathrm{h}^{-1}\right)\end{array}$ & Temperature Reference \\
\hline $\begin{array}{l}\text { Nitrososphaera viennensis } \\
\text { Ca. Nitrosotalea sinensis }\end{array}$ & AOA & 0.033 s.e. 0.002 & 0.030 s.e. 0.002 & 0.023 & $35^{\circ} \mathrm{C}$ & Tourna et al. (2011) \\
$\begin{array}{l}\text { Ca. Nitrosocosmicus franklandus } \\
\text { Nitrosomonas europaea ATCC 25978 }\end{array}$ & AOA & 0.022 s.e. 0.002 & 0.026 s.e. 0.000 & 0.025 & $35{ }^{\circ} \mathrm{C}$ & Lehtovirta-Morley et al. (2014) \\
Nitrosospira multiformis ATCC 25196 & AOB & 0.061 s.e. 0.001 & 0.060 s.e. 0.002 & 0.066 & $28{ }^{\circ} \mathrm{C}$ & Shaw et al. (2006) \\
Nitrosospira tenuis $\mathrm{NV} 12$ & AOB & 0.050 s.e. 0.004 & 0.051 s.e. 0.004 & 0.035 & $28{ }^{\circ} \mathrm{C}$ & Shaw et al. (2006) \\
Nitrosospira briensis 128 & AOB & 0.039 s.e. 0.001 & 0.042 s.e. 0.001 & 0.03 & $28{ }^{\circ} \mathrm{C}$ & Shaw et al. (2006) \\
\hline & AOB & 0.034 s.e. 0.001 & 0.035 s.e. 0.000 & 0.03 & $28{ }^{\circ} \mathrm{C}$ & Shaw et al. (2006) \\
\hline
\end{tabular}

(Skinner and Walker 1961) containing phenol red $\mathrm{pH}$ indicator, which was periodically readjusted to $\mathrm{pH} 8$ with $5 \%$ (wt/ vol) $\mathrm{Na}_{2} \mathrm{CO}_{3}$.

\section{BNI preparation and supplementation}

Three root-derived BNIs [methyl 3-(4-hydroxyphenyl) propionate (MHPP), 1,9-decanediol (DD) and sakuranetin (SKNT)] and three shoot-derived BNIs [methyl linoleate (ML), linoleic acid (LA) and linolenic acid (LNA)] were investigated (see Supplementary Fig. 1 for chemical structures). MHPP, ML, LA, LNA and SKNT were obtained from SigmaAldrich $\odot$ and DD from Molport, USA. Stock solutions of all chemicals were prepared in $100 \%$ dimethyl sulfoxide (DMSO). Ten microlitres of stock solution was added to $10 \mathrm{ml}$ medium, resulting in $0.1 \%$ (vol/vol) DMSO with BNI at concentrations in the range $0.2-5000 \mu \mathrm{M}$, as required.

\section{Microbial growth and BNI inhibition}

All cultures were grown in $20 \mathrm{ml}$ liquid medium in $30-\mathrm{ml}$ universal bottles, incubated statically in the dark at $35^{\circ} \mathrm{C}$ and $28{ }^{\circ} \mathrm{C}$ for AOA and AOB strains, respectively. Growth was determined by assaying $\mathrm{NO}_{2}{ }^{-}$concentration (using Griess test, Shinn 1941) twice daily for 1 week. All treatments were carried out in triplicate. Maximum specific growth rate $\left(\mu_{\max }\right)$ was assessed as the slope of log-linear plots of nitrite concentration vs. time, using data from at least four time points during exponential nitrite production. Initial growth experiments were performed to test potential effects of DMSO, which was used to solubilise BNIs, determining the $\mu_{\max }$ of each AO as described above after supplementation of medium with $0.1 \%$ DMSO. Inhibition was quantified as the percentage reduction in $\mu_{\max }$ in the presence of DMSO ( $\mu_{\text {DMSO }}$ ) (Eq. 1).

Percentage inhibition $=100-\left(\frac{\mu_{\text {DMSO }}}{\mu_{\text {NoDMSO }}}\right) \times 100$
The inhibition of a particular strain by BNIs was assessed as the reduction in $\mu_{\max }$ in BNI-supplemented medium as a percentage of the $\mu_{\max }$ of that strain in the presence of DMSO ( $\mu_{\text {DMSO }}^{\text {avg }}$ ) (determined using Eq. 2).

Percentage inhibition $=100-\left(\frac{\mu_{\mathrm{BNI}}}{\mu_{\mathrm{DMSO}}^{\text {avg }}}\right) \times 100$

The concentration of each BNI leading to $80 \%$ inhibition $\left(\mathrm{IC}_{80}\right)$ was determined from a plot of percentage inhibition vs. BNI concentration, using data from at least four concentrations and assuming a linear relationship between percentage inhibition and inhibitor concentration (see Supplementary Tables S1, S2, S3, S4, S5, S6, S7 and S8). The $\mu_{\max }$ and $\mathrm{IC}_{80}$ were determined separately for each individual replicate.

\section{Statistical analysis}

The significance of the effect of DMSO on each AO was tested using analysis of variance followed by Tukey post hoc analysis. Hypotheses were tested by comparing the $\mathrm{IC}_{80}$ values obtained for each strain growing in the presence of each BNI using a multiple pairwise Student's $t$ test with the $p$ value adjusted for Bonferroni correction. Prior to analysis of variance, the homoscedasticity and normality of data distribution were assessed. Hypothesis $\mathrm{H} 1$, that AOA are more sensitive to BNIs than $\mathrm{AOB}$, was tested by comparing the $\mathrm{IC}_{80}$ values for $\mathrm{AOA}$ and $\mathrm{AOB}$. Hypothesis $\mathrm{H} 2$, that $\mathrm{AOA}$ and $\mathrm{AOB}$ respond differently to BNIs from roots and shoots, was tested by comparing the $\mathrm{IC}_{80}$ values for BNIs from the two sources. Hypothesis H3, assessing the validity of $N$. europaea as a model for bioassay of AO inhibition by BNIs, was tested by comparing $\mathrm{IC}_{80}$ values of $N$. europaea with those of other strains for each BNI. All pairwise Student's $t$ tests were performed in R (R Core Team 2017) using the packages "tidyr" (Wickham and Henry 2019) and "dplyr" (Wickham et al. 2019). R package "ggplot2" (Wickham 2016) was used to plot the results. 


\section{Results}

\section{$A O A$ are more sensitive to BNIs than AOB}

The potential inhibition of AO growth by DMSO was investigated by comparison of $\mu_{\max }$ of three AOA and four AOB in the presence and absence of $0.1 \%$ DMSO (Table 1). DMSO significantly reduced the $\mu_{\max }$ of $N$. viennensis by $9 \%$ ( $p=$ $10^{-14}$ ). The $\mu_{\max }$ of all other strains was not significantly affected by the addition of DMSO (Table 1, Supplementary Fig. 2). The percentage inhibition of each strain increased linearly with increasing BNI concentration up to $\sim 90 \%$ inhibition; this linear relationship was used to estimate the BNI concentration resulting in $80 \%$ reduction in $\mu_{\max }\left(\mathrm{IC}_{80}\right.$ ) (Supplementary Tables S1, S2, S3, S4, S5, S6, S7 and S8). H1 proposed that AOA were more sensitive than AOB to BNIs, with the null hypothesis that AOA and AOB sensitivities are not significantly different. Indeed, AOA sensitivity to BNIs was significantly higher than for AOB $\left(p=0.2 \times 10^{-5}\right)$, with mean $\mathrm{IC}_{80}$ values of 201 and $506 \mu \mathrm{M}$, respectively (Fig. 1).

\section{BNI inhibition varies between strains and with BNI source}

There was no significant difference in overall AO sensitivity to BNIs produced by roots and shoots across all treatments (Fig. 2a). However, while there was no significant difference in inhibition between $\mathrm{AOA}$ and $\mathrm{AOB}$ for the root-derived BNIs, AOA were significantly more sensitive than AOB to shoot-derived BNIs $\left(p=1.59 \times 10^{-12}\right)$ (Fig. 2b, Supplementary Table S9), providing only partial support for hypothesis $\mathrm{H} 2$, that $\mathrm{AOA}$ and $\mathrm{AOB}$ respond differently to BNIs. Within each $\mathrm{AO}$ group, $\mathrm{IC}_{80}$ values for $\mathrm{AOA}$ were significantly lower for the three shoot-derived BNIs, LA, LNA and ML, and two root-derived BNIs, DD and SKNT, with values of 15 s.e. 19,11 s.e. 9, 18 s.e. 6,377 s.e. 269 and 119 s.e. $77 \mu \mathrm{M}$ respectively, compared to AOB at 510 s.e. 201, 259 s.e. 79,832 s.e. 259,793 s.e. 500 and 354 s.e. 255 $\mu \mathrm{M}$, respectively, where s.e. represents standard error (Fig. 2c, Supplementary Table S10). However, AOB were significantly more sensitive than AOA to the root-derived BNI MHPP, with $\mathrm{IC}_{80}$ values of 287 s.e. 214 and 667 s.e. $405 \mu \mathrm{M}$ respectively (Fig. 2c). The relative sensitivities of AOA and AOB were significantly different for each BNI with AOA being more sensitive than AOB to 5 of the 6 tested BNIs (all except MHPP), irrespective of the source (Fig. 2c, Supplementary Table S11).

The inhibition by root-derived BNIs was strain-dependent for both AOA and AOB (Fig. 3). The inhibition by shootderived BNIs was also strain-dependent for AOB, but not for AOA (Fig. 3). Inhibition of $N$. europaea varied with BNIs and was significantly different from that of AOA for all of the BNIs tested, confirming the hypothesis H3 that

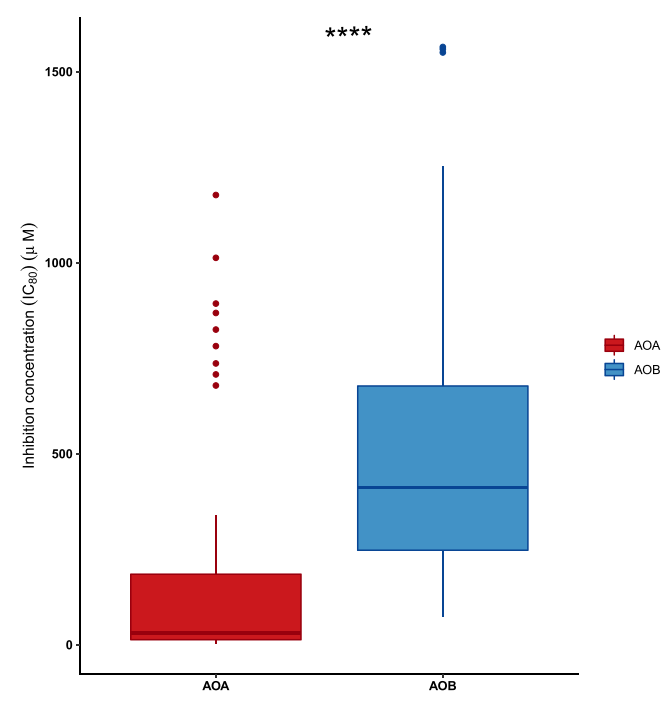

Fig. 1 BNI concentration resulting in $80 \%$ inhibition $\left(\mathrm{IC}_{80}\right)$ of $\mathrm{AOA}$ and $\mathrm{AOB}$ for all BNIs. Data are presented as box plots, and $* * * *$ denotes significant difference $\left(p=0.2 \times 10^{-5}\right)$ in $\mathrm{IC}_{80}$ between $\mathrm{AOA}$ and $\mathrm{AOB}$, when tested by pairwise Student's $t$ test

$N$. europaea is not a good model for bioassay of AO inhibition by BNIs. In addition, the inhibition of $N$. europaea was similar to the inhibition of one AOB strain ( $N$. multiformis), but only for 2 out of 6 BNIs tested. Overall, the inhibition of $N$. europaea was significantly different from that of other AOB strains (Fig. 3, Supplementary Table S12).

\section{Discussion}

\section{$A O A$ are more sensitive than $A O B$ to $B N I s$}

Hypothesis $\mathrm{H} 1$ predicted that AOA would be more sensitive than AOB to BNIs, based on reported greater sensitivity of AOA in soil planted with some $B$. humidicola genotypes (Subbarao et al. 2009). Within both AOA and AOB, there was a considerable strain variation in inhibitory concentrations, and relative sensitivities differed between BNIs. However, as a group, AOA were significantly more sensitive than $\mathrm{AOB}$ to BNIs and were more sensitive to five of the six BNIs investigated. The exception was MHPP, for which. $N$. viennensis and $\mathrm{Ca}$. N. sinensis were less sensitive than the other strains, although $\mathrm{Ca}$. franklandus was more sensitive than the four AOB strains. Strain variation in sensitivity has been observed within AOA and AOB for different SNIs (e.g. Taylor et al. 2013; Wright et al. 2020; Zhao et al. 2020) and may be related to the chemical structure of the compound. For example, Shen et al. (2013) reported a greater sensitivity of AOA for the aromatic SNI, nitrapyrin, but the reverse situation for linear SNIs allylthiourea (ATU), amidinothiourea (ASU) and dicyandiamide (DCD). In addition, differences in sensitivities of AOA and AOB to alkynes of different chain length provide the basis for use of octyne as a differential inhibitor of 

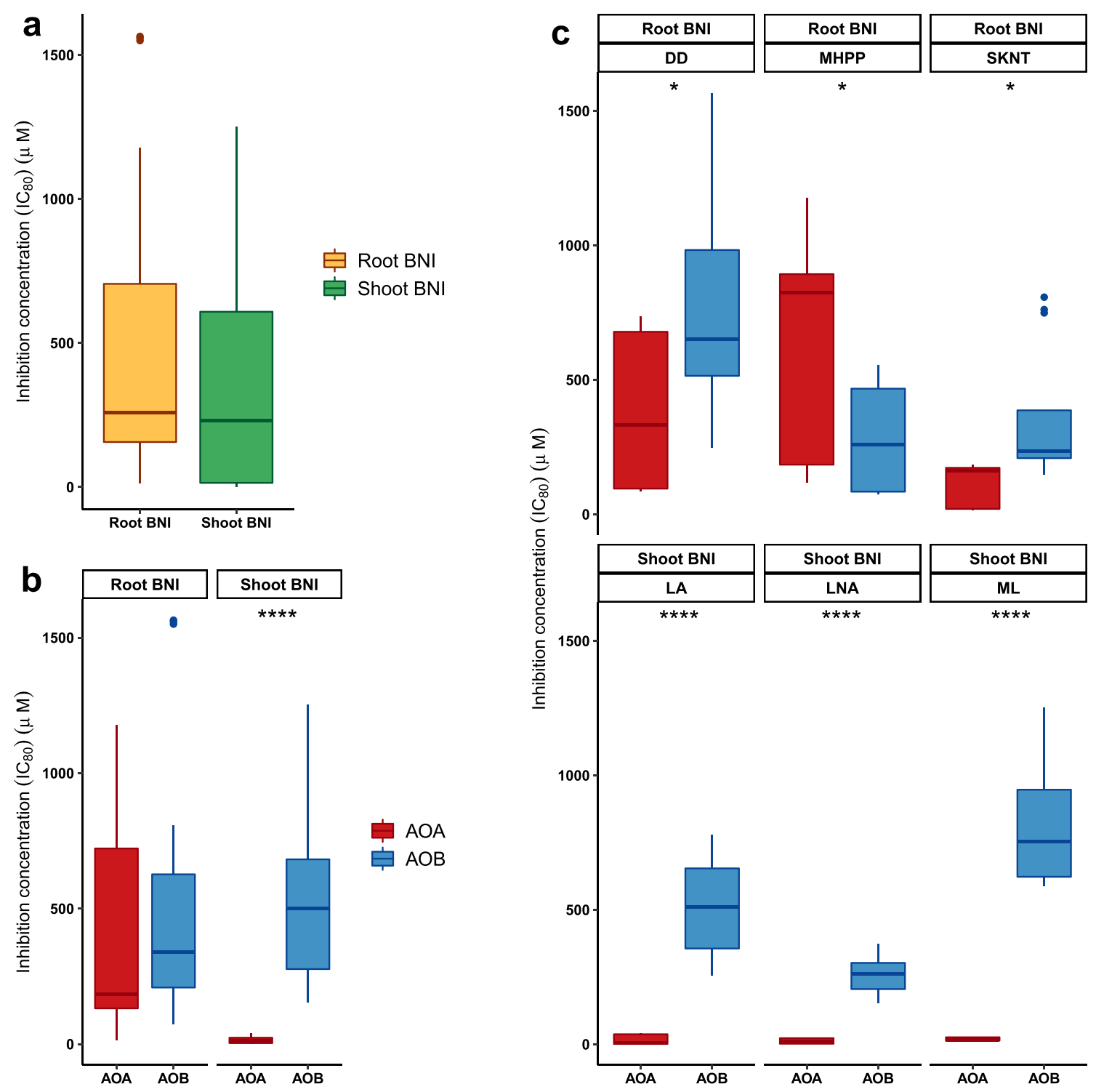

Fig. 2 a Inhibitory concentrations $\left(\mathrm{IC}_{80}\right)$ of root- and shoot-derived BNIs for all $\mathrm{AO}$ investigated. b Differences in $\mathrm{IC}_{80}$ of root- and shoot-derived $\mathrm{BNIs}$ for $\mathrm{AOA}$ and $\mathrm{AOB}$. $\mathrm{c}$ Differences in $\mathrm{IC}_{80}$ for $\mathrm{AOA}$ and $\mathrm{AOB}$ for each BNI. BNI abbreviations correspond to 1,9-decanediol (DD), sakuranetin (SKNT), methyl 3-(4-hydroxyphenyl) propionate (MHPP),

AOB (Taylor et al. 2013). The chemical structure may influence the mechanism of inhibition of ammonia monooxygenase which may stem from the differences in the enzyme's active site (Wright et al. 2020), but there is currently no evidence for the specific effects of chemical structure on inhibition.

\section{BNI inhibition is dependent on BNI source}

Hypothesis $\mathrm{H} 2$ predicted greater sensitivity of $\mathrm{AOB}$ to rootderived BNIs and similar responses of AOA and AOB to those derived from shoots, based on evidence for possible selection of $\mathrm{AOA}$, rather than $\mathrm{AOB}$, in the rhizosphere. There was, however,

linoleic acid (LA), linolenic acid (LNA) and methyl linoleate (ML). Data are presented as box plots, and asterisks $*$ and $* * * *$ denote significant differences in $\mathrm{IC}_{80}$ with $p<0.01$ and $p<10^{-8}$, respectively, within each subplot when tested by pairwise Student's $t$ test

little evidence for these predictions. There was no significant difference in the sensitivity of AOA and AOB to the three root-derived BNIs, when treated as a group, but effects varied within BNIs, with greater sensitivity of AOA for DD (from rice) and SKNT (from sorghum), but greater sensitivity of AOB to MHPP (also from sorghum). This suggests that the chemical nature of the BNI may be more important for resistance than adaptation of AOA to growth in the rhizosphere and that any selection for AOA in the rhizosphere is not due to increased resistance to BNIs. In contrast, AOA were significantly more sensitive than AOB to all three shoot-derived BNIs investigated. The inhibitory concentrations of shoot-derived fatty acids LNA and LA were similar within each group, potentially through 


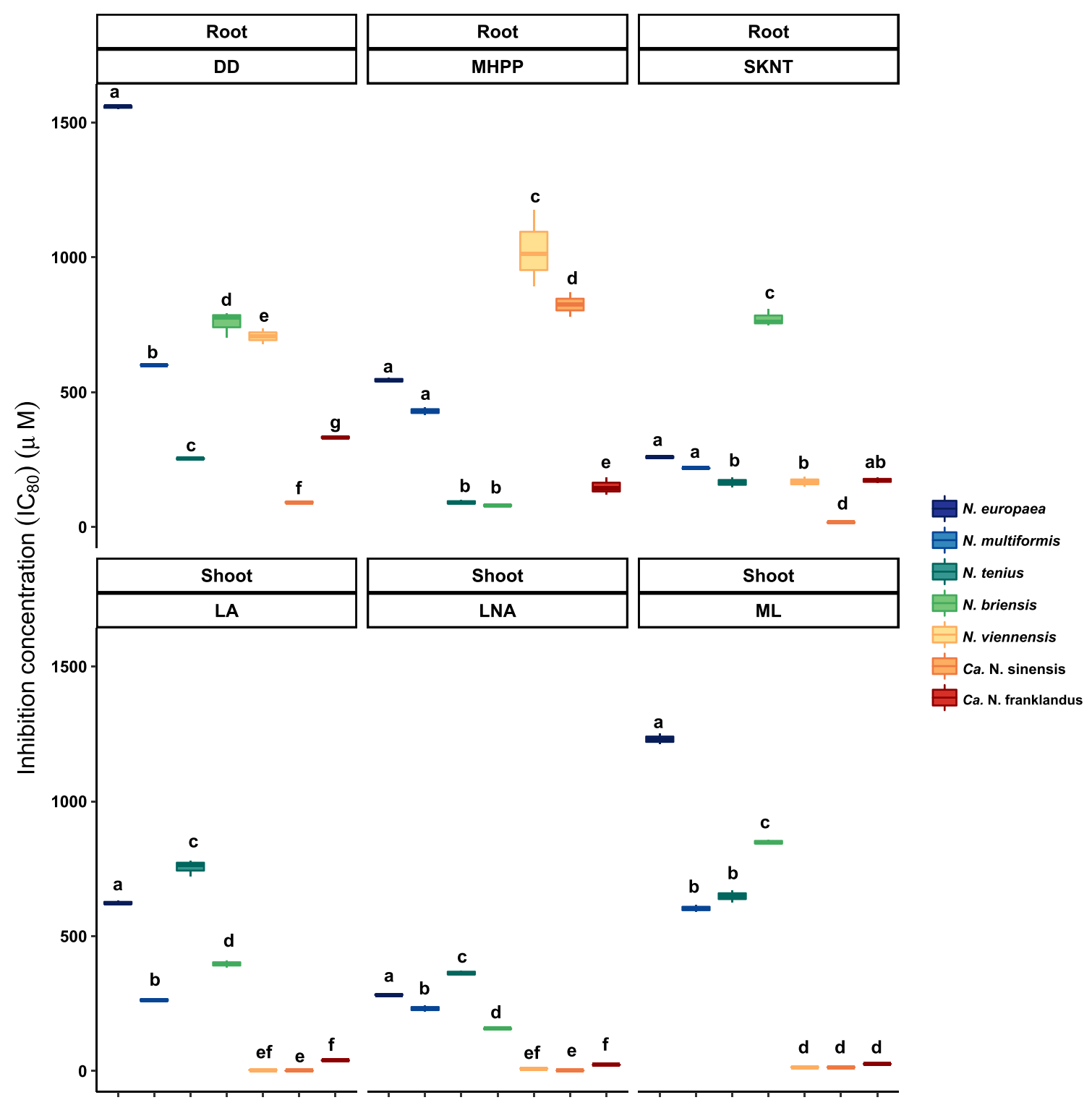

Fig. 3 BNI concentration resulting in $80 \%$ inhibition of $\mu_{\max }\left(\mathrm{IC}_{80}\right)$. BNIs investigated were 1,9-decanediol (DD), sakuranetin (SKNT), methyl 3-(4-hydroxyphenyl) propionate (MHPP), linoleic acid (LA), linolenic acid (LNA) and methyl linoleate (ML) for each ammoniaoxidiser strain tested in this study. Strains in each subplot are, from left

similarities in chemical structure (Supplementary Fig. 1) implying a similar mode of action for inhibition, as previously observed (Subbarao et al. 2008).

\section{Choice of ammonia oxidisers for BNI bioassays}

Although $N$. europaea is the most extensively studied bacterial ammonia oxidiser, it is common in sediments and wastewater treatment plants but rare in soil, raising concerns regarding its ecological relevance in bioassays for BNIs in soil. Our findings demonstrate significant variation in sensitivity to $\mathrm{BNI}$ both within and between $\mathrm{AOA}$ and $\mathrm{AOB}$ and significant to right, AOB N. europaea, $N$. multiformis, $N$. tenuis and $N$. briensis and AOA $N$. viennensis, $C a$. N. sinensis and $C a$. N. franklandus. Data are presented as box plots, and different letters denote significant differences $(p<0.05)$ in inhibitory concentration $\left(\mathrm{IC}_{80}\right)$ within each subplot (i.e. for each BNI) when tested by pairwise Student's $t$ test

differences between sensitivity of $N$. europaea and strains that are more representative of natural soil AO communities (Fig. 3 ). The significant differences in inhibitory concentrations for different strains certainly suggest that a wider range of representative organisms is required for bioassays, rather than relying on a single strain.

A similar variation in relative sensitivities of individual strains to different BNIs also suggests that, without greater understanding of mechanisms of inhibition, generalisations cannot be made from studies of individual BNIs. This, combined with the niche partitioning amongst AOA and AOB, complicates BNI application in soil 
systems when inhibition studies are based on a single microorganism. Certainly, the greater resistance of AOA to MHPP observed in this study is consistent with the dominance of soil ammonia oxidation by AOA and reports of much greater concentrations of MHPP required to inhibit soil nitrification than in $N$. europaea bioassays (Subbarao et al. 2012). We therefore suggest that future BNI testing should involve several ammonia-oxidiser strains of both AOA and AOB to obtain an accurate picture of the potential effectiveness of BNIs in suppressing soil nitrifier activity, soil nitrification and $\mathrm{N}_{2} \mathrm{O}$ emissions.

A number of studies reported differences between BNI potential determined in bioassays in pot experiments and field studies. For example, the inhibition of nitrification by DD and MHPP in soil differed significantly from the inhibition in culture bioassays (Sun et al. 2016; Lu et al. 2019). Sakuranetin, a BNI produced by sorghum, also strongly inhibited activity in bioassays, but not in soil incubations (Subbarao et al. 2012). In contrast, $N$. europaea is much more resistant to nitrapyrin in soil (Powell and Prosser 1986), in part through cell attachment to clay minerals (Powell and Prosser 1992). Lu et al. (2019) also suggested that AOA and AOB inhibition varied with soil $\mathrm{pH}$ and with $\mathrm{AO}$ community composition and complexity. A number of factors may influence inhibitory concentrations in soil. These discrepancies may be due to protection from inhibition by cells attached to soil particulate matter and/ or in biofilms and/or to differences in abiotic characteristics, e.g. temperature, $\mathrm{pH}$, to degradation of inhibitors and other factors. However, increasing knowledge of AO soil community ecology, niche partitioning and the influence of plants, soil conditions and overall microbial community activity (e.g. via competition, mineralisation) on $\mathrm{AO}$ communities suggest that differences in strain sensitivity to BNIs will be important in designing relevant bioassays and assessing the potential efficiencies of BNIs in soil. Future testing of both additional ammonia-oxidiser cultures and BNIs yet to be discovered is encouraged to better determine the effectiveness of the different sources of BNIs. This study demonstrates the significant limitations of reliance on a single bioassay strain that is not representative of natural soil AO communities. It also highlights the need for greater understanding of mechanisms of inhibition of BNIs as well as of the factors influencing differences in inhibition in laboratory culture and in the soil environment.

Supplementary Information The online version contains supplementary material available at https://doi.org/10.1007/s00374-020-01533-1.

Acknowledgements We thank Dr. Alex Douglas for the valuable discussion on the analysis of data in $\mathrm{R}$.

Funding JKB is funded by a University of Aberdeen PhD studentship, and CGR is funded by a Royal Society University Research Fellowship (URF150571).

\section{Compliance with ethical standards}

Conflict of interest The authors declare that they have no conflict of interest.

Open Access This article is licensed under a Creative Commons Attribution 4.0 International License, which permits use, sharing, adaptation, distribution and reproduction in any medium or format, as long as you give appropriate credit to the original author(s) and the source, provide a link to the Creative Commons licence, and indicate if changes were made. The images or other third party material in this article are included in the article's Creative Commons licence, unless indicated otherwise in a credit line to the material. If material is not included in the article's Creative Commons licence and your intended use is not permitted by statutory regulation or exceeds the permitted use, you will need to obtain permission directly from the copyright holder. To view a copy of this licence, visit http://creativecommons.org/licenses/by/4.0/.

\section{References}

Ai C, Liang G, Sun J, Wang X, He P, Zhou W (2013) Different roles of rhizosphere effect and long-term fertilization in the activity and community structure of ammonia oxidizers in a calcareous fluvoaquic soil. Soil Biol Biochem 57:30-42. https://doi.org/10.1016/j. soilbio.2012.08.003

Aigle A, Prosser JI, Gubry-Rangin C (2019) The application of highthroughput sequencing technology to analysis of amoA phylogeny and environmental niche specialisation of terrestrial bacterial ammonia-oxidisers. Environ Microbiome 14:3. https://oi.org/10.1186/ s40793-019-0342-6

Chen X-P, Zhu Y-G, Xia Y, Shen J-P, He J-Z (2008) Ammonia-oxidizing archaea: important players in paddy rhizosphere soil? Environ Microbiol 10:1978-1987. https://doi.org/10.1111/j.1462-2920. 2008.01613.x

Coskun D, Britto DT, Shi W, Kronzucker HJ (2017) Nitrogen transformations in modern agriculture and the role of biological nitrification inhibition. Nat Plants 3:17074. https://doi.org/10.1038/nplants. 2017.74

Gubry-Rangin C, Hai B, Quince C, Engel M, Thomson B, James P, Schlöter M, Griffiths R, Prosser JI, Nicol GW (2011) Niche specialization of terrestrial archaeal ammonia oxidizers. Proc Natl Acad Sci U S A 108:21206-21211. https://doi.org/10.1073/pnas.1109000108

Gubry-Rangin C, Nicol GW, Prosser JI (2010) Archaea rather than bacteria control nitrification in two agricultural acidic soils. FEMS Microbiol Ecol 74:566-574. https://doi.org/10.1111/j.1574-6941. 2010.00971.x

Harms H, Koops HP, Wehrmann H (1976) An ammonia-oxidizing bacterium, Nitrosovibrio tenuis nov. gen. nov. sp. Arch Microbiol 108: 105-111. https://doi.org/10.1007/bf00425099

Hink L, Gubry-Rangin C, Nicol GW, Prosser JI (2018) The consequences of niche and physiological differentiation of archaeal and bacterial ammonia oxidisers for nitrous oxide emissions. ISME J 12:10841093. https://doi.org/10.1038/s41396-017-0025-5

Iizumi T, Mizumoto M, Nakamura K (1998) A bioluminescence assay using Nitrosomonas europaea for rapid and sensitive detection of nitrification inhibitors. Appl Environ Microbiol 64:3656-3662. https://doi.org/10.1128/aem.64.10.3656-3662.1998

IPCC (2014) Climate Change 2014: synthesis report. Contribution of working groups I. II and III to the Fifth report of the intergovernmental panel of climate change, Geneva 
Ke X, Angel R, Lu Y, Conrad R (2013) Niche differentiation of ammonia oxidizers and nitrite oxidizers in rice paddy soil. Environ Microbiol 15:2275-2292. https://doi.org/10.1111/1462-2920.12098

Lehtovirta-Morley LE, Ge CR, Ross J, Yao HY, Nicol GW, Prosser JI (2014) Characterisation of terrestrial acidophilic archaeal ammonia oxidisers and their in- hibition and stimulation by organic compounds. FEMS Microbiology Ecology 89:542-552

Lehtovirta-Morley LE, Ross J, Hink L, Weber E, Gubry-Rangin C, Thion C, Prosser JI, Nicol GW (2016) Isolation of 'Candidatus Nitrosocosmicus franklandus', a novel ureolytic soil archaeal ammonia oxidiser with tolerance to high ammonia concentration. FEMS Microbiol Ecol 92:fiw057. https://doi.org/10.1093/femsec/ fiw057

Lehtovirta-Morley LE, Stoecker K, Vilcinskas A, Prosser JI, Nicol GW (2011) Cultivation of an obligate acidophilic ammonia oxidizer from a nitrifying acid soil. Proc Natl Acad Sci U S A 108:1589215897. https://doi.org/10.1073/pnas.1107196108

Lu Y, Zhang X, Jiang J, Kronzucker HJ, Shen W, Shi W (2019) Effects of the biological nitrification inhibitor 1,9-decanediol on nitrification and ammonia oxidizers in three agricultural soils. Soil Biol Biochem 129:48-59. https://doi.org/10.1016/j.soilbio.2018.11.008

Nardi P, Akutsu M, Pariasca-Tanaka J, Wissuwa M (2012) Effect of methyl 3-4-hydroxyphenyl propionate, a Sorghum root exudate, on $\mathrm{N}$ dynamic, potential nitrification activity and abundance of ammonia-oxidizing bacteria and archaea. Plant Soil 367:627-637. https://doi.org/10.1007/s11104-012-1494-y

O'Sullivan CA, Fillery IRP, Roper MM, Richards RA (2016) Identification of several wheat landraces with biological nitrification inhibition capacity. Plant Soil 404:61-74. https://doi.org/10.1007/ s11104-016-2822-4

Powell SJ, Prosser JI (1986) Inhibition of ammonium oxidation by nitrapyrin in soil and liquid culture. Appl Environ Microbiol 52: 782-787. https://doi.org/10.1128/aem.52.4.782-787.1986

Powell SJ, Prosser JI (1992) Protection of Nitrosomonas europaea colonizing clay minerals from inhibition by nitrapyrin. J Gen Microbiol 137:1923-1929. https://doi.org/10.1099/00221287-137-8-1923

Prosser JI, Hink L, Gubry-Rangin C, Nicol GW (2019) Nitrous oxide production by ammonia oxidizers: physiological diversity, niche differentiation and potential mitigation strategies. Glob Chang Biol 26:103-118. https://doi.org/10.1111/gcb.14877

Prosser JI, Nicol GW (2012) Archaeal and bacterial ammonia-oxidisers in soil: the quest for niche specialisation and differentiation. Trends Microbiol 20:523-531. https://doi.org/10.1016/j.tim.2012.08.001

R Core Team (2017) R: A language and environment for statistical computing. R Foundation for Statistical Computing, Vienna URL http:// www.R-project.org/

Rice MC, Norton JM, Valois F, Bollmann A, Bottomley PJ, Klotz MG, Laanbroek HJ, Suwa Y, Stein LY, Sayavedra-Soto L, Woyke T, Shapiro N, Goodwin LA, Huntemann M, Clum A, Pillay M, Kyrpides N, Varghese N, Mikhailova N, Markowitz V, Palaniappan K, Ivanova N, Stamatis D, Reddy TBK, Ngan CY, Daum C (2016) Complete genome of Nitrosospira briensis C-128, an ammonia-oxidizing bacterium from agricultural soil. Stand Genomic Sci 11:46. https://doi.org/10.1186/s40793-016-0168-4

Ruser R, Schulz R (2015) The effect of nitrification inhibitors on the nitrous oxide $\left(\mathrm{N}_{2} \mathrm{O}\right)$ release from agricultural soils - a review. $J$ Plant Nutr Soil Sci 178:171-188. https://doi.org/10.1002/jpln. 201400251

Shaw L, Nicol GW, Smith Z, Fear J, Prosser JI, Baggs E (2006) Nitrosospira spp. can produce nitrous oxide via a nitrifier denitrification pathway. Environ Microbiol 8:214-222. https://doi.org/10. 1111/j.1462-2920.2005.00882.x

Shen T, Stieglmeier M, Dai J, Urich T, Schleper C (2013) Responses of the terrestrial ammonia-oxidizing archaeon $\mathrm{Ca}$. Nitrososphaera viennensis and the ammonia-oxidizing bacterium Nitrosospira multiformis to nitrification inhibitors. FEMS Microbiol Lett 344: 121-129. https://doi.org/10.1111/1574-6968.12164

Shinn MB (1941) Colorimetric method for determination of nitrate. In Eng Chem Anal Ed 13:33-35. https://doi.org/10.1021/i560089a010

Skinner FA, Walker N (1961) Growth of Nitrosomonas europaea in batch and continuous culture. Arch Mikrobiol 38:339-349. https:// doi.org/10.1007/BF0040800

Song GC, Im H, Jung J, Lee S, Jung MY, Rhee SK, Ryu CM (2019) Plant growth-promoting archaea trigger induced systemic resistance in Arabidopsis thaliana against Pectobacterium carotovorum and Pseudomonas syringae. Environ Microbiol 21:940-948. https:// doi.org/10.1111/1462-2920.14486

Stein LY (2019) Insights into the physiology of ammonia-oxidizing microorganisms. Curr Opin Chem Biol 49:9-15. https://doi.org/10. 1016/j.cbpa.2018.09.003

Subbarao GV, Nakahara K, Hurtado MP, Ono H, Moreta DE, Salcedo AF, Yoshihashi AT, Ishikawa T, Ishitani M, Ohnishi-Kameyama M, Yoshida M, Rondon M, Rao IM, Lascano CE, Berry WL, Ito O (2009) Evidence for biological nitrification inhibition in Brachiaria pastures. Proc Natl Acad Sci U S A 106:17302-17307. https://doi.org/10.1073/pnas.0903694106

Subbarao GV, Nakahara K, Ishikawa T, Ono H, Yoshida M, Yoshihashi T, Zhu Y, Zakir HAKM, Deshpande SP, Hash CT, Sahrawat KL (2012) Biological nitrification inhibition (BNI) activity in sorghum and its characterization. Plant Soil 366:243-259. https://doi.org/10. 1007/s11104-012-1419-9

Subbarao GV, Nakahara K, Ishikawa T, Yoshihashi AT, Ito O, Ono H, Ohnishi-Kameyama M, Yoshida M, Kawano N, Berry WL (2008) Free fatty acids from the pasture grass Brachiaria humidicola and one of their methyl esters as inhibitors of nitrification. Plant Soil 313:89-99. https://doi.org/10.1007/s11104-008-9682-5

Subbarao GV, Rondon M, Ito O, Ishikawa T, Rao IM, Nakahara K, Lascano C, Berry WL (2006) Biological nitrification inhibition (BNI) - is it a widespread phenomenon? Plant Soil 294:5-18. https://doi.org/10.1007/s11104-006-9159-3

Subbarao GV, Yoshihashi T, Worthington M, Nakahara K, Ando Y, Sahrawat KL, Rao IM, Lata JC, Kishii M, Braun HJ (2015) Suppression of soil nitrification by plants. Plant Sci 233:155-164. https://doi.org/10.1016/j.plantsci.2015.01.012

Sun L, Lu Y, Yu F, Kronzucker HJ, Shi W (2016) Biological nitrification inhibition by rice root exudates and its relationship with nitrogenuse efficiency. New Phytol 212:646-656. https://doi.org/10.1111/ nph. 14057

Taffner J, Cernava T, Erlacher A, Berg G (2019) Novel insights into plant-associated archaea and their functioning in arugula (Eruca sativa Mill). J Adv Res 19:39-48. https://doi.org/10.1016/j.jare. 2019.04 .008

Taylor AE, Vajrala N, Giguere AT, Gitelman AI, Arp DJ, Myrold DD, Sayavedra-Soto L, Bottomley PJ (2013) Use of aliphatic-alkynes to discriminate soil nitrification activities of ammonia-oxidizing Thaumarchaea and bacteria. Appl Environ Microbiol 79:65446551. https://doi.org/10.1128/AEM.01928-13

Thion CE, Poirel JD, Cornulier T, De Vries FT, Bardgett RD, Prosser JI (2016) Plant nitrogen-use strategy as a driver of rhizosphere archaeal and bacterial ammonia oxidiser abundance. FEMS Microbiol Ecol 92:fiw091. https://doi.org/10.1093/femsec/fiw091

Tourna M, Stieglmeier M, Spang A, Könneke M, Schintlmeister A, Urich T, Engel M, Schloter M, Wagner M, Richter A, Schleper C (2011) Nitrososphaera viennensis, an ammonia oxidizing archaeon from soil. Proc Natl Acad Sci U S A 108:8420-8425. https://doi.org/10. 1073/pnas. 1013488108

Wattenburger CJ, Gutknecht J, Zhang Q, Brutnell T, Hofmockel K, Halverson L (2020) The rhizosphere and cropping system, but not arbuscular mycorrhizae, affect ammonia oxidizing archaea and bacteria abundances in two agricultural soils. Appl Soil Ecol 151: 103540. https://doi.org/10.1016/j.apsoil.2020.103540 
Wickham H (2016) ggplot2: elegant graphics for data analysis. SpringerVerlag, New York

Wickham H, Francois R, Henry L, Muller K (2019) dplyr: a grammar of data manipulation. $\mathrm{R}$ package version 0.8.0.1. https://CRAN.Rproject.org/package $=$ dplyr

Wickham H, Henry L (2019) tidyr: easily tidy data with 'spread()' and 'gather()' functions. R package version 0.8.3. https://CRAN.Rproject.org/package=tidyr

Wright CL, Schatteman A, Crombie AT, Murrell JC, Lehtovirta-Morley LE (2020) Inhibition of ammonia monooxygenase from ammonia- oxidizing archaea by linear and aromatic alkynes. Appl Environ Microbiol 86:e2388-e02319. https://doi.org/10.1128/aem.02388-19

Zhao J, Bello MO, Meng Y, Prosser JI, Gubry-Rangin C (2020) Selective inhibition of ammonia oxidising archaea by simvastatin stimulates growth of ammonia oxidising bacteria. Soil Biol Biochem 141: 107673. https://doi.org/10.1016/j.soilbio.2019.107673

Publisher's note Springer Nature remains neutral with regard to jurisdictional claims in published maps and institutional affiliations. 